\title{
Independence of Firing Correlates of Anatomically Proximate Hippocampal Pyramidal Cells
}

\author{
A. David Redish, ${ }^{1,2}$ Francesco P. Battaglia, ${ }^{1}$ Monica K. Chawla, ${ }^{1}$ Arne D. Ekstrom, ${ }^{1}$ Jason L. Gerrard, ${ }^{1}$ \\ Peter Lipa, ${ }^{1}$ Ephron S. Rosenzweig, ${ }^{1}$ Paul F. Worley, ${ }^{3}$ John F. Guzowski, ${ }^{1}$ Bruce L. McNaughton, ${ }^{1}$ and \\ Carol A. Barnes ${ }^{1}$ \\ ${ }^{1}$ Division of Neural Systems, Memory, and Aging, Arizona Research Laboratories, University of Arizona, Tucson, Arizona \\ 85724, ${ }^{2}$ Department of Neuroscience, University of Minnesota, Minneapolis, Minnesota 55455, and ${ }^{3}$ Department of \\ Neuroscience and Neurology, The Johns Hopkins University, Baltimore, Maryland 21205
}

In neocortex, neighboring neurons frequently exhibit correlated encoding properties. There is conflicting evidence whether a similar phenomenon occurs in hippocampus. To assess this quantitatively, a comparison was made of the spatial and temporal firing correlations within and between local groups of hippocampal cells, spaced 350-1400 $\mu \mathrm{m}$ apart. No evidence of clustering was found in a sample of $>3000$ neurons. Moreover, cells active in two environments were uniformly interspersed at

Hippocampal pyramidal cell activity correlates with both spatial and nonspatial variables. The hippocampus does exhibit a coarse topographical organization in its intrinsic and extrinsic connections (Amaral, 1993), and broad septotemporal gradients of encoding have also been documented (Jung et al., 1994). The cellular properties of close neighbors, however, tend to exhibit uncorrelated patterns of activity under a variety of conditions. Clear examples of this include studies in which cells were recorded in different environments (O'Keefe and Nadel, 1978; Kubie and Ranck, 1983; Muller and Kubie, 1987; Thompson and Best, 1989; Guzowski et al., 1999), in which either internal (Markus et al., 1995; Knierim et al., 1998) or external (O'Keefe and Nadel, 1978; Bostock et al., 1991; Sharp et al., 1995; Skaggs and McNaughton, 1998) salient cues are altered in an environment or in which animals had impaired neuroplasticity (Rotenberg et al., 1996; Barnes et al., 1997). In fact, it has generally proven impossible to predict the firing correlates of a given hippocampal pyramidal cell in one context from its properties in other contexts with dissimilar spatial cues. This is in contrast to other brain areas, such as sensory neocortex, in which local clusters of neurons frequently exhibit correlated encoding properties and in which a high degree of response invariance across spatial and behavioral context is often observed (Mountcastle, 1956). Theoretical proposals suggest that, to make arbitrary associations in different contexts and to maximize storage capacity

\footnotetext{
Received Oct. 19, 2000; revised Jan. 4, 2001; accepted Jan. 4, 2001.

This work was supported by National Institutes of Health Grants MH01565, AG12609, and AG09219. A.D.R. was partially supported by National Research Service Award Grant AG05805, and J.L.G. was partially supported by a grant from the Arizona chapter of the Achievement Reward for College Scientists Foundation. We thank Joe Bohanick, Sam deDios, Jennifer Dees, Rowena D'Monte, Jeri Meltzer, Matt Suster, Karen-Weaver Sommers, and Joyce Yuan for help with conducting experiments. We thank R. E. Hampson for providing unpublished procedural details from Hampson et al. (1999).

Correspondence should be addressed to Dr. Carol A. Barnes, Life Sciences North, Room 384, University of Arizona, Tucson, AZ 85724. E-mail: carol@nsma.arizona.edu.
}

Copyright (C) 2001 Society for Neuroscience $\quad 0270-6474 / 01 / 210001-06 \$ 15.00 / 0$ a scale of $<100 \mu \mathrm{m}$, as assessed by the activity-induced gene Arc. Independence of encoding characteristics implies uncorrelated inputs, which could enhance the capacity of the hippocampus to store arbitrary associations.

Key words: hippocampus; topography; place cell; spatial firing correlate; nonspatial firing correlate; tetrode; Arc; immediate early gene by recoding similar inputs into dissimilar representations, the synaptic drive on neighboring hippocampal pyramidal neurons should not be correlated (Marr, 1969; McNaughton, 1989; Cohen and Eichenbaum, 1993; McClelland et al., 1995; Redish, 1999). This independence of firing correlates across contexts is incompatible with a large-scale tendency for anatomically neighboring neurons to exhibit correlated firing.

Two lines of evidence suggest that there might be some degree of clustering of firing rate correlations within the hippocampus. First, several in vitro studies have revealed the existence of lowresistance gap junctions among small clusters (two to three cells) of pyramidal and granule cells (MacVicar and Dudek, 1980; Rao et al., 1987). Such junctions are thought to increase the likelihood of correlated discharges at short time scales. Second, Hampson et al. (1999) reported recently that hippocampal neuronal response properties exhibit strong, periodic clustering; cells responding selectively to opposite sides of their experimental environment appeared to occur in bands 600-800 $\mu \mathrm{m}$ wide, and nonspatial correlates clustered in even finer bands. An earlier study (Eichenbaum et al., 1989) reported an anatomical clustering of placespecific firing properties at a scale of $\sim 1 \mathrm{~mm}$. In contrast, O'Keefe et al. (1998) reported no relationship between waveform parameters and place fields of 15 cells recorded on a single tetrode.

This article is published in The Journal of Neuroscience, Rapid Communications Section, which publishes brief, peerreviewed papers online, not in print. Rapid Communications are posted online approximately one month earlier than they would appear if printed. They are listed in the Table of Contents of the next open issue of JNeurosci. Cite this article as: JNeurosci, 2001, 21:RC134 (1-6). The publication date is the date of posting online at www.jneurosci.org.

http://www.jneurosci.org/cgi/content/full/5093 
Because of the incompatibility of these results and the importance of this question for the empirical and theoretical hippocampal literature, we reinvestigated this phenomenon.

If cells with overlapping spatial selectivities do cluster in wide bands as reported by Hampson et al. (1999) and Eichenbaum et al. (1989), then cells close enough together to be recorded from a single probe should have significantly more similar firing correlates than cells located 350-1400 $\mu \mathrm{m}$ apart. Similarly, if cells with overlapping nonspatial selectivities cluster in regular bands of 200-400 $\mu \mathrm{m}$, as reported by Hampson et al. (1999), then pairs of cells recorded from a single probe should show correlated fluctuations in firing rate. We examined this question by recording cell ensembles with multiple tetrodes at a lattice spacing of 350 $\mu \mathrm{m}$ (see Fig. 1).

We also examined the question of topography in the hippocampus by imaging recent cell activity using in situ hybridization of the activity-induced immediate-early gene $\operatorname{Arc}$ (see Fig. 4). Arc RNA first appears in intranuclear foci shortly after neuronal activation (within $5 \mathrm{~min}$ ) and then disappears from the intranuclear foci and appears in the cytoplasm after $\sim 20$ min (Guzowski et al., 1999). This change in signal permits the differentiation of recently active cells from cells active 20-30 min earlier. We used this time course to measure cell activity within two environments (one experienced 30 min before the animal was killed, and one experienced $5 \mathrm{~min}$ before). If a topography exists, then these two populations should separate when measured at very small scales $(100 \times 100 \times 20 \mu \mathrm{m})$.

Parts of this paper have been published previously in abstract form (Redish et al., 2000a).

\section{MATERIALS AND METHODS}

Tetrode studies. Twenty-eight male, Fischer-344 rats (9-30 months of age) were used. Each animal was implanted with a hyperdrive, a device allowing the individual manipulation of 12 tetrodes and two reference probes. Tetrodes were arranged in four rows of three, four, four, and three electrodes spaced in a $350 \mu \mathrm{m}$ lattice, with $\sim 1.4 \mathrm{~mm}$ maximal distance between tetrodes (Fig. 1). Tetrodes consisted of four $14 \mu \mathrm{m}$ insulated nichrome wires wound together (McNaughton et al., 1983; O'Keefe and Recce, 1993; Wilson and McNaughton, 1993). Animal care and surgeries were conducted in accordance with National Institutes of Health guidelines (for surgical details see Gothard et al., 1996). Animals were maintained above $80 \%$ ad libitum feeding weight. Water was available ad libitum at all times.

All tasks consisted of variations on animals running for food or medial forebrain bundle stimulation on elevated tracks. In task A, rats ran around a rectangular maze $(93 \times 43 \times 10 \mathrm{~cm}$ track $)$ receiving food at two of the four corners. Two groups of animals were tested. One group (group A1) performed the task for two sessions of 25 min each, separated by an intermediate rest session or a session on another maze (for procedural details, see Barnes et al., 1997). The two sessions were analyzed separately. The intermediate session was not analyzed. The other group (group A2) performed the task for one 30 min session (for procedural details see Ekstrom et al., 1999). Position was parameterized to the angle on a circle centered on the center of the track for analysis. Analyses for task A were done using circular statistics.

In task B, rats shuttled back and forth on a linear track $(180 \times 16 \mathrm{~cm})$ for two 30 min sessions separated by a 20 min rest period in a small box adjacent to the track (for procedural details see Redish et al., 2000b). Rats received food at only one end of the track, but had to reach the other end for food to be available. A goal was also available at which animals could receive medial forebrain bundle stimulation. Position was linearized for analysis.

Task C was topologically identical to task B, but the track was circular (44 $\mathrm{cm}$ radius, $10 \mathrm{~cm}$ wide track); for procedural details see Rosenzweig et al. (1999). As with task B, rats in task C ran from a box to a barrier and back for two $30 \mathrm{~min}$ sessions, separated by a $20 \mathrm{~min}$ rest period in a box adjacent to the track. Because the animals did not complete the circle on each lap, position was unwrapped, producing a linear value between $0^{\circ}$

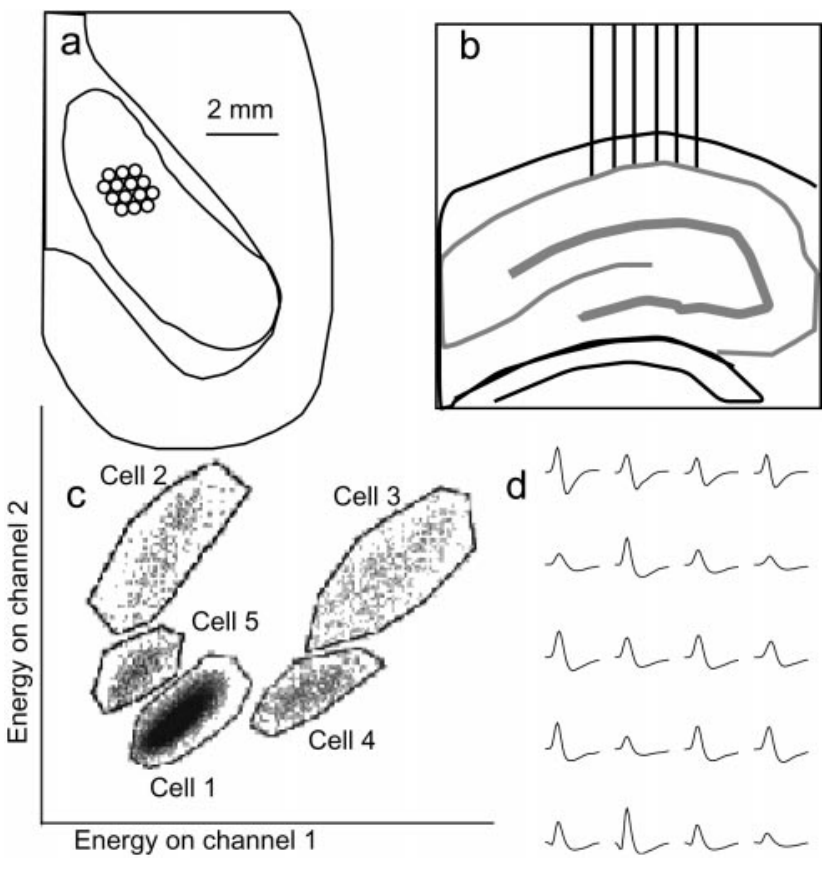

Figure 1. Neuronal ensemble recording configuration in hippocampus. $a$, Diagram of dorsal view of right hippocampus illustrating the spacing of the tetrode array positioned over dorsal CA1. Each small circle indicates one tetrode. The array was arranged in four rows of three, four, four, and three electrodes. Each tetrode was separated by $350 \mu \mathrm{m}$, and the maximal distance across the array was $\sim 1.4 \mathrm{~mm}$. $b$, Diagram of the typical trajectories of the tetrode recording probes. Note that, because the hippocampus curves significantly in this region, individually adjustable probes are necessary to have all probes located at the same relative depth within the pyramidal cell layer. A planar array positioned in the pyramidal layer would sample from different depths at the ends than the middle, thus resulting in a periodic sampling bias. $c$, Two dimensions of the spike parameter space from a typical tetrode recording within CA1 pyramidal field. This recording simultaneously resolved one interneuron (Cell 1, dense cluster; firing rate of 30 spikes/sec) and four pyramidal cells (Cells $2-5$, sparse clusters; firing rate of $0.2-0.5 \mathrm{spikes} / \mathrm{sec}$ ). On large, single-wire electrodes, spikes from pyramidal cells would often be difficult to distinguish from spikes from interneurons. $d$, Average spike wave shapes of the cells illustrated in c. Cell 1 corresponds to the top trace, and Cell 5 corresponds to the bottom trace.

and $359^{\circ}$. As with task B, a goal was available at which animals could receive medial forebrain bundle stimulation.

It should be noted that task $\mathrm{A}$ only required the animals to run around the track, while tasks $\mathrm{B}$ and $\mathrm{C}$ were complex goal-finding tasks that required a correct sequence of goal-directed paths to receive reward.

Waveforms were filtered between 600 and $6000 \mathrm{~Hz}$ and recorded from Discovery (task A, group 1; DataWave, Boulder, CO) or Cheetah (task A, group 2, and tasks B and C; Neuralynx, Tucson, AZ) recording systems. For recording details see Gothard et al. (1996). Putative cells were separated using manual clustering algorithms (McNaughton et al., 1989; XClust, M. Wilson, MIT, Cambridge, MA; MClust, A. D. Redish). Cells were categorized as pyramidal or interneurons based on properties of firing rate, interspike interval histograms, and spike waveform shape (Ranck, 1973; O'Keefe and Nadel, 1978; Markus et al., 1995). Only cells categorized as putative pyramidal were included in our analyses. Position was tracked from light-emitting diodes on a headstage on the animal's head via a ceiling camera at $20 \mathrm{~Hz}$ (task A, group 1) or at $60 \mathrm{~Hz}$ (task A, group 2, tasks B and C).

Upper bounds for $95 \%$ confidence intervals for each distribution were found by adding the Kolmogorov-Smirnov $D$ statistic corresponding to the $5 \%$ error bound to the sample distribution (D'Agostino and Stephens, 1986). Lower bounds were found by subtracting the same $D$ statistic from the sample distribution. The space between these upper and lower bounds form the $95 \%$ confidence interval for the real distribution from which the sample has been taken. 
(a)

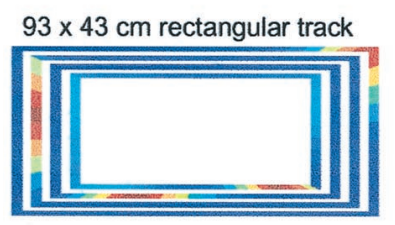

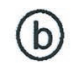

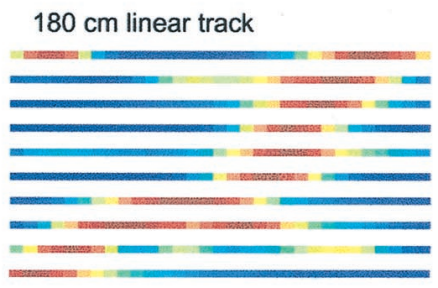

(C)

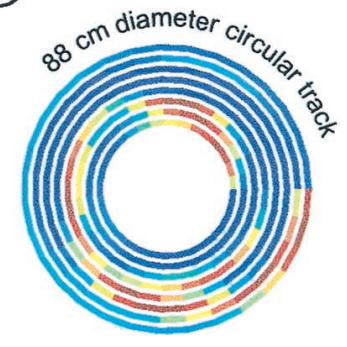

Figure 2. Distribution of place fields recorded from sample tetrodes. Each panel shows the distribution recorded from a different tetrode (in a different rat) under a different experimental condition. In all panels, red indicates high-firing rate, and blue indicates lowfiring rate. $a$, Rectangular track $93 \times 43 \mathrm{~cm}$; each concentric rectangle indicates firing of a different cell along the same retangular track. $b$, Linear track $180 \mathrm{~cm}$; each row indicates a different cell. $c$, Circular track $44 \mathrm{~cm}$ diameter; each concentric circle indicates firing of a different cell along the same circular track.
Arc studies. Three male Fischer-344 rats ( 9 months of age) were used. Each rat was exposed to a novel environment (A) for $5 \mathrm{~min}$, returned to his home cage for $20 \mathrm{~min}$, and then exposed to a second novel environment (B) for $5 \mathrm{~min}$. Both environments were of similar size $\left(3600 \mathrm{~cm}^{2}\right)$ but were located in different rooms, each with unique local and distal cues. Immediately after the B exploration session, the rats were killed by decapitation using a rodent guillotine, and the brains were rapidly removed and flash-frozen in liquid isopentane. Coronal brain sections $(20$ $\mu \mathrm{m}$ ) containing the dorsal hippocampus (approximately $-3.6 \mathrm{~mm}$ from bregma) were collected on slides. Fluorescent in situ hybridization for Arc RNA was performed, and $z$-series image stacks from the CA1 region were obtained by confocal microscopy. Three populations of cells positive for $A r c$ RNA were found: cells showing $A r c$ RNA only in discrete intranuclear foci (group 1), cells that showed Arc RNA only in the cytoplasm (group 2), and cells showing Arc RNA in both intranuclear foci and in the cytoplasm (group 3). Environment A responsive cells were defined as those in groups 2 and 3; environment B responsive cells were defined as those in groups 1 and 3 . The data analyzed here originally formed part of a larger study. For full details of animal handling, in situ hybridization, and confocal microscope analysis, see Guzowski et al. (1999).

\section{RESULTS}

The database used for the analysis of unit correlations consisted of 3074 spike trains, recorded from 933 tetrodes in 28 rats over 165 sessions under three different experimental conditions. Not including tetrodes from which no cells were recorded, an average of 3.3 cells were recorded from each tetrode (SD of 2.7 cells per tetrode). This database produced 8362 intratetrode cell pairs (i.e., both cells of the pair recorded simultaneously on the same tetrode) and 43,724 simultaneously recorded cell pairs (i.e., both cells of the pair recorded simultaneously, on either the same or different tetrodes).

In all three experiments, place fields from cells recorded from single tetrodes were observed to cover the environment. Figure 2 shows the distribution of place fields from representative sample tetrodes from each of the three experiments. Clustering withintetrode was quantitatively compared with clustering betweentetrode using three measurements: distribution of spatial-firing field centers, correlations between place fields, and correlations between firing rate fluctuations. As described below, these measures indicate that there is virtually no anatomical clustering of spatial or temporal firing characteristics among dorsal hippocampal CA1 pyramidal cells.

The spatial-firing field center for each cell was defined as the mean of all locations where the animal was when the cell fired a spike, weighted by the number of spikes fired at each location, in which location was a one-dimensional variable corresponding to the position along the principal path of the track. For those tracks in which animals ran in a loop (tasks A and C), circular mean was used (see Materials and Methods). The spread of the distribution of field centers of cells recorded from a single tetrode was measured as the SD of those field centers. To avoid making any assumptions about the distribution of fields within a task, a Monte Carlo bootstrap resampling was done taking $n$ cells from the entire population to estimate the expected variance for a tetrode from which $n$ cells were recorded. (Five hundred resamples were done for each $n$.) Less than $8 \%$ of the tetrodes were significantly more clustered than predicted by the bootstrap at a threshold of $p=0.05$ using an $F$ test, providing no indication of clustering in the population.

This spatial-firing field center analysis is biased toward the center of the environment (Muller et al., 1987). However, that bias is in the direction of increased clustering. Because no clustering was seen, it is unlikely to have affected our results. However, the spatial-firing field center analysis also assumes that each
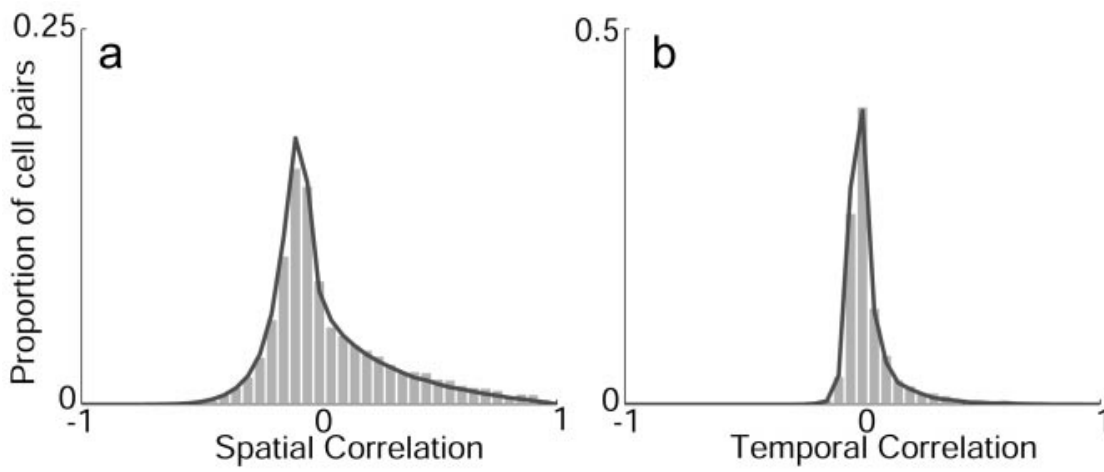

Figure 3. Correlations of firing patterns of cell pairs recorded on the same and on different tetrodes. $a$, Comparison between distribution of correlations of place fields of pairs of cells recorded from the same tetrode and the distribution of correlations of place fields, independent of tetrode. For each pyramidal cell on each tetrode, the place field was found (dividing space into 64 bins, summing the total spikes occurring within each bin, and normalizing by the time the animal occupied that bin). Correlations between a pair of cells was measured by the correlation coefficient between the two place fields. Gray bars show distribution of correlations between pairs recorded from the same tetrode; solid black line shows distribution of pairs independent of tetrode. A Kolomogorov-Smirnov test did not find a significant difference between the distri-

butions (two-sample test; $p>0.8$ ). $b$, Comparison between distribution of correlations of firing fluctuations of cell pairs recorded from the same tetrode and the distribution of cell pairs recorded independent of tetrode. Firing activity was binned into $500 \mathrm{msec}$ time windows. The distribution of correlations of firing fluctuations of pairs recorded from the same tetrode (gray bars) followed closely the correlations of pairs independent of tetrode (solid line). This analysis makes no assumptions about whether firing correlates are predominantly spatial or nonspatial. A Kolomogorov-Smirnov test did not find a significant difference between the distributions (two-sample test; $p>0.8$ ). The same analysis using a temporal bin size of $50 \mathrm{msec}$ similarly failed to provide evidence of clustering (data not shown). 
cell only shows a single, uni-modal place field. Because cells are known to have multiple fields, an alternative analysis (direct correlations; see below) was also done that does not make this assumption. The alternative analysis also does not have the bias noted by Muller et al. (1987).

Another method for measuring whether place fields recorded from a single tetrode tend to cluster or not is to examine directly the correlation between place fields. The within-tetrode correlations can be compared with the expected correlations, measured by taking all pairs of pyramidal cells recorded within an experiment, independent of which tetrode the cell was recorded on. Figure $3 a$ shows that the distribution of within-tetrode correlations was not significantly different from the expected correlation distribution over the three tasks (Kolomogorov-Smirnov twosample test; $p>0.8$ ). Ninety-five percent confidence intervals placed on the two distributions (see Materials and Methods) never differed by $>15 \%$, implying that the distribution of spatial correlations between cell pairs recorded from the same tetrode was very similar to the distribution of spatial correlations between cell pairs recorded across tetrodes.

Finally, if encoding properties cluster, then, at timescales relevant to the encoding process, fluctuations in firing rates of neighboring cells should be correlated. This hypothesis is independent of any assumptions about the nature of the encoded variables per se (e.g., spatial vs nonspatial). Correlations between firing rates measured over $500 \mathrm{msec}$ time windows were made for cell pairs recorded on the same tetrode (within-tetrode) and compared with the distribution of correlations for all pairs recorded within a session (i.e., independent of tetrode). As can be seen in Figure $3 b$, the distribution of within-tetrode correlations did not significantly differ from the expected distribution (KolomogorovSmirnov two-sample test; $p>0.8$ ). Ninety-five percent confidence intervals placed on the two distributions (see Materials and Methods) never differed by $>7 \%$, implying the distribution of temporal correlations between cell pairs recorded from the same tetrode was very similar to the distribution of temporal correlations between cell pairs recorded across tetrodes. Similarly, no evidence was found for clustering when $50 \mathrm{msec}$ time windows were used.

Arc is an immediate-early gene that is dynamically regulated by neural activity (Lyford et al., 1995; Guzowski et al., 1999). Arc RNA signal appears in discrete intranuclear foci in $\sim 40 \%$ of CA1 neurons within $5 \mathrm{~min}$ of exposure to a novel, $3600 \mathrm{~cm}^{2}$ environment and then shifts to a cytoplasmic localization within the next 25 min (Guzowski et al., 1999). This translocation allows neurons active shortly before being killed to be differentiated from neurons active 20-30 min earlier. Three animals were exposed to two different environments (A and B) for 5 min each with a $20 \mathrm{~min}$ delay in between. Using high-sensitivity fluorescent in situ hybridization and laser-scanning confocal microscopy, it is possible to differentiate $A r c$ intranuclear foci from Arc cytoplasmic mRNA. As shown by Guzowski et al. (1999), the pattern of Arc gene expression in CA1 neurons meets predictions derived from hippocampal ensemble recording studies of place cells; in rats exposed to the same environment twice, a single population of cells contained nuclear and cytoplasmic signal for Arc RNA. In contrast, in rats exposed to two different environments, two statistically independent cell populations were detected. If a topography such as Hampson et al. (1999) suggested exists, then ensembles active in environment $\mathrm{A}$ should tend to be at least partially anatomically separate from ensembles active in environment $\mathrm{B}$. Figure 4 shows that the proportion of cells active in each envi-

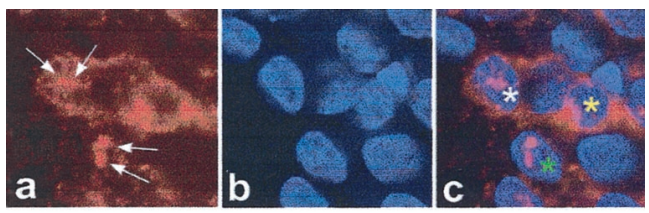

RAT NUMBER

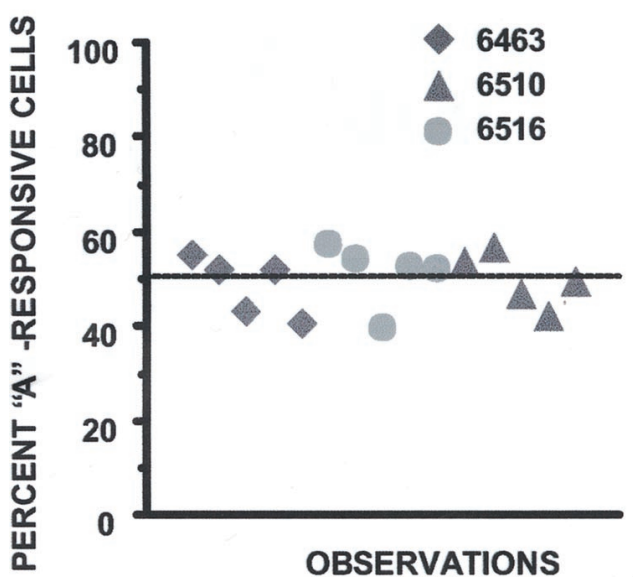

Figure 4. Neuronal activity measured with the immediate-early gene Arc. Environment A and B responsive neurons were intermixed at the cellular level within single coronal sections. Rats were exposed to two distinct environments (A and B) for 5 min each with a 20 min separation between the two experiences. Animals were killed immediately after the second experience, and brains were processed for fluorescent in situ hybridization for Arc RNA. Serial $1 \mu \mathrm{m}$ optical sections from $20-\mu \mathrm{m}$-thick coronal sections were obtained by confocal microscopy and analyzed as described in Materials and Methods. Top, A $1 \mu \mathrm{m}$ optical section showing A- and B-responsive cells within a single $65 \times 65 \mu \mathrm{m}$ region. $a$, Detection of Arc RNA staining alone (red, detection with CY3). Arc intranuclear foci are indicated by arrows. $b$, Detection of nuclear staining alone (blue, detection with 4'-6'-Diamidino-2-phenylindole). c, Overlay image of $A r c$ RNA and nuclear staining, showing a cell active solely in environment A (Arc cytoplasmic staining only, yellow asterisk), a cell active solely in environment B (intranuclear Arc foci only, green asterisk), and a cell active in both environments (both intranuclear and cytoplasmic Arc staining, white asterisk). Bottom, The number of CA1 cells analyzed per image region ranged from 19 to 32, and the number of CA1 cells analyzed per rat ranged from 117 to 134 . Data for individual $100 \times 100 \mu \mathrm{m}$ regions are shown as the percentage of environment A-responsive cells out of the sum of A- and B-responsive cells. Note that A and B cells are uniformly distributed within each region for each rat; neither A nor B cells clustered in any given region.

ronment was essentially constant across all CA1 pyramidal layer image regions analyzed from all animals (did not significantly differ from chance; $\chi^{2}=9.69$; df $=14 ; p>0.75$, indicating no significant clustering tendency). In all image fields analyzed, the cells active in the two environments were highly intermixed (Fig. 4).

\section{DISCUSSION}

Neither high-resolution ensemble recording methods (Figs. 1-3) nor direct cellular imaging of activity traces (Fig. 4) suggest topography in the distribution of firing correlates in the hippocampus. Hampson et al. (1999) reported clustering of firing correlates at a 200-800 $\mu \mathrm{m}$ resolution. In the experiments reported here, no clustering was found at any resolution measured (ranging from $<100 \mu \mathrm{m}$, Arc study, to $350-1400 \mu \mathrm{m}$, tetrode studies).

Although we are unable to reconcile these results with those of Hampson et al. (1999), four possible explanations cannot be ruled out. First, Hampson et al. used a delayed nonmatch-to-sample 
(DNMS) task, whereas the experiments reported here consisted of animals running on narrow, elevated tracks (tetrode studies) and of animals exploring a pair of $3600 \mathrm{~cm}^{2}$, open environments (Arc studies). Although the environments used in the tetrode studies were all narrow tracks, some of the tasks (tasks B and C) were complicated goal-finding tasks (Redish et al., 2000b; Rosenzweig et al., 1999). Therefore, we found no evidence for topography in either simple or complex tasks, nor did we find evidence for topography in thin tracks or in open environments. It is possible that the DNMS protocol somehow accessed a topography hidden in the hippocampal system that is not evident in other tasks, but this seems rather implausible.

Second, our analysis techniques do not depend on a registration of electrode arrays from animal to animal; the tetrode techniques used in this paper all depend on multiple cells being recorded from each tetrode. Because the devices used by Hampson et al. were fixed arrays of single electrodes, they had a much lower yield of simultaneously recorded cells, including per electrode (this study, 3.3 cells per tetrode; Hampson et al., 0.66 cells per electrode), per session (this study, 18.6 cells per session; Hampson et al., 10.6 cells per session), and per animal (this study, 109.8 cells per animal; Hampson et al., 10.6 cells per animal). The lower yield forced Hampson et al. to register array locations across animals. It is possible that their registration techniques might have affected their results.

Third, the hippocampus shows two processing states, indicated by different EEG rhythms (Vanderwolf, 1971; Ranck, 1973; O'Keefe and Nadel, 1978; Buzsáki et al., 1983): theta, indicated by a $7-10 \mathrm{~Hz}$ rhythm, and LIA, indicated by irregular activity punctuated by $100 \mathrm{msec}$ sharp waves. The theta rhythm appears during movement and other attentive behaviors, whereas LIA appears during slow-wave sleep and resting behaviors (Vanderwolf, 1971; O’Keefe and Nadel, 1978; Buzsáki et al., 1983). Hippocampal pyramidal cells show place fields during theta, but during LIA, cells fire during sharp waves, independent of the location of the animal (O'Keefe and Nadel, 1978; Thompson and Best, 1989; Wilson and McNaughton, 1994; Kudrimoti et al., 1999). In the experiments reported here, only states occuring during theta (groups A1 and A2) or during movement (groups B and $\mathrm{C}$, movement is indicative of theta) were included in our analyses. Hampson et al. (1999), however, did not report any controls to separate LIA and theta. The spatial firing reported by Hampson et al. (1999) occured while the animals were sitting at the levers (spatial firing was measured by perievent histograms aligned to the lever-press response). Because animals were not moving, it is possible that their hippocampi were in the LIA rather than the theta state. Sharp waves observed in CA1 are triggered by a population burst of CA3 cells (Buzsáki et al., 1983; Ylinen et al., 1995). It is possible that, if the population burst in CA3 were not uniformly distributed, then the CA1 firing patterns during LIA might not be uniformly distributed. It is also conceivable that some of the weak topography in the CA3 to CA1 connectivity (Amaral, 1993; Witter, 1993) may produce some weak topography during sharp waves that is not present during theta states. However, to date, there is no physiological evidence supporting these conjectures. Even if a weak topography did exist during sharp waves, this would not provide an explanation for the periodicity reported by Hampson et al. (1999).

Finally, the methods used by Hampson et al. (1999) do not enable effective single-unit isolation, and therefore their putative cells may have consisted of mixtures of spikes from multiple cells of different classes. Interneurons and pyramidal cells in the hip- pocampus have different firing properties and activity correlates (Ranck, 1973; O'Keefe and Nadel, 1978; Kubie and Ranck, 1983). Morphologically differentiable interneurons are also distributed in different proportions at different levels near and within the hippocampal pyramidal cell layers (Freund and Buzsáki, 1996). Because the electrode array used by Hampson et al. was planar, whereas the hippocampus is not, it is possible that the different electrodes in their array consistently reached different relative depths, thus recording from different cell populations in a periodic manner with a resulting periodicity of firing correlation. Because there is a population of interneurons preferentially found just superficial or just inferior to the pyramidal layers (Freund and Buzsáki, 1996), very small changes (as small as $50-100 \mu \mathrm{m})$ can make a difference as to whether the record is dominated by pyramidal cells or interneurons. In the studies reported here, each tetrode was independently placed in stratum pyramidale as indicated by large $200 \mathrm{~Hz}$ ripples in the multiunit local field potential (Ylinen et al., 1995), and only cells with pyramidal characteristics were included in the analyses (Ranck, 1973; O’Keefe and Nadel, 1978; Markus et al., 1995). Similarly, only anatomically identified pyramidal cells were included in the Arc in situ analyses.

The data reported here showed no indication that the firing correlates of hippocampal pyramidal cells located anatomically near each other are any more correlated than predicted by chance. It is thus unlikely that the inputs to neighboring dorsal hippocampal pyramidal cells are significantly correlated or that the presence of low-resistance gap junctions in those same cells leads to a significant increase in correlated firing, at least during active behavior. This independence of encoding properties of neighboring neurons would enhance the ability of the hippocampus to store arbitrary associations and would maximize its storage capacity.

\section{REFERENCES}

Amaral DG (1993) Emerging principles of intrinsic hippocampal organization. Curr Opin Neurobiol 3:225-229.

Barnes CA, Suster MS, Shen J, McNaughton BL (1997) Multistability of cognitive maps in the hippocampus of old rats. Nature 388:272-275.

Bostock E, Muller RU, Kubie JL (1991) Experience-dependent modifications of hippocampal place cell firing. Hippocampus 1:193-206.

Buzsáki G, Leung LW, Vanderwolf CH (1983) Cellular bases of hippocampal EEG in the behaving rat. Brain Res 287:139-171.

Cohen NJ, Eichenbaum H (1993) Memory, amnesia, and the hippocampal system. Cambridge, MA: MIT.

D'Agostino RB, Stephens MA (1986) Goodness-of-fit techniques. New York: Marcel Dekker.

Eichenbaum H, Wiener SI, Shapiro ML, Cohen NJ (1989) The organization of spatial coding in the hippocampus: a study of neural ensemble activity. J Neurosci 9:2764-2775.

Ekstrom AD, Quinn L, Meltzer J, Teed RGW, McNaughton BL, Barnes CA (1999) The NMDA antagonist CPP blocks hippocampal place field expansion in the behaving rat. Soc Neurosci Abstr 25:2166.

Freund TF, Buzsáki G (1996) Interneurons of the hippocampus. Hippocampus 6:345-370.

Gothard KM, Skaggs WE, McNaughton BL (1996) Dynamics of mismatch correction in the hippocampal ensemble code for space: interaction between path integration and environmental cues. J Neurosci 16:8027-8040.

Guzowski JF, McNaughton BL, Barnes CA, Worley PF (1999) Environment-specific expression of the immediate-early gene $A R C$ in hippocampal neuronal ensembles. Nat Neurosci 2:1120-1124.

Hampson RE, Simeral JD, Deadwyler SA (1999) Distribution of spatial and nonspatial information in dorsal hippocampus. Nature 402:610-614.

Jung MW, Wiener SI, McNaughton BL (1994) Comparison of spatial firing characteristics of the dorsal and ventral hippocampus of the rat. J Neurosci 14:7347-7356.

Knierim JJ, Kudrimoti HS, McNaughton BL (1998) Interactions between idiothetic cues and external landmarks in the control of place cells and head direction cells. J Neurophysiol 80:425-446.

Kubie JL, Ranck Jr JB (1983) Sensory-behavioral correlates in individual hippocampus neurons in three situations: space and context. In: 
Neurobiology of the hippocampus (Seifert W, ed), pp 433-447. New York: Academic.

Kudrimoti HS, Barnes CA, McNaughton BL (1999) Reactivation of hippocampal cell assemblies: effects of behavioral state, experience, and EEG dynamics. J Neurosci 19:4090-4101.

Lyford GL, Yamagata K, Kaufmann WE, Barnes CA, Sanders LK, Copeland NG, Gilbert DJ, Jenkins NA, Lanahan AA, Worley PF (1995) Arc, a growth factor and activity-related gene, encodes a novel cytoskeleton-associated protein that is enriched in neuronal dendrites. Neuron 14:433-445.

MacVicar BA, Dudek FE (1980) Dye-coupling between CA3 pyramidal cells in slices of rat hippocampus. Brain Res 196:494-497.

Markus EJ, Oin Y, Leonard B, Skaggs WE, McNaughton BL, Barnes CA (1995) Interactions between location and task affect the spatial and directional firing of hippocampal neurons. J Neurosci 15:7079-7094.

Marr D (1969) A theory of cerebellar cortex. J Physiol (Lond) 202:437-470.

McClelland JL, McNaughton BL, O'Reilly RC (1995) Why there are complementary learning systems in the hippocampus and neocortex: insights from the successes and failures of connectionist models of learning and memory. Psychol Rev 102:419-457.

McNaughton BL (1989) Neuronal mechanisms for spatial computation and information storage. In: Neural connections, mental computation (Nadel L, Cooper L, Culicover P, Harnish RM, eds), pp 285-350. Cambridge, MA: MIT.

McNaughton BL, Barnes CA, O'Keefe J (1983) The contributions of position, direction, and velocity to single unit activity in the hippocampus of freely-moving rats. Exp Brain Res 52:41-49.

McNaughton BL, Barnes CA, Meltzer J, Sutherland RJ (1989) Hippocampal granule cells are necessary for normal spatial learning but not for spatially-selective pyramidal cell discharge. Exp Brain Res 76:485-496.

Mountcastle VB (1956) Modality and topographic properties of single neurons of cat's somatic sensory cortex. J Neurophysiol 20:408-434.

Muller RU, Kubie JL (1987) The effects of changes in the environment on the spatial firing of hippocampal complex-spike cells. J Neurosci 7:1951-1968

Muller RU, Kubie JL, Ranck Jr JB (1987) Spatial firing patterns of hippocampal complex-spike cells in a fixed environment. J Neurosci 7:1935-1950

O'Keefe J, Nadel L (1978) The hippocampus as a cognitive map. Oxford: Clarendon.

O'Keefe J, Recce M (1993) Phase relationship between hippocampal place units and the EEG theta rhythm. Hippocampus 3:317-330.

O'Keefe J, Burgess N, Donnett JG, Jeffery KJ, Maguire EA (1998) Place cells, navigational accuracy, and the human hippocampus. Philos Trans R Soc Lond B Biol Sci 353:1333-1340.

Ranck Jr JB (1973) Studies on single neurons in dorsal hippocampus formation and septum in unrestrained rats. I. Behavioral correlates and firing repertoires. Exp Neurol 41:461-555.

Rao G, Barnes CA, McNaughton BL (1987) Occlusion of hippocampal electrical junctions by intracellular calcium injection. Brain Res 408:267-270.

Redish AD (1999) Beyond the cognitive map: from place cells to episodic memory. Cambridge MA: MIT.

Redish AD, Battaglia FP, Ekstrom AD, Gerrard JL, Lipa P, Rosenzweig ES, McNaughton BL, Barnes CA (2000a) Hippocampal pyramidal cells located near each other anatomically do not show related spatial firing correlates. Soc Neurosci Abstr 26:982.

Redish AD, Rosenzweig ES, Bohanick JD, McNaughton BL, Barnes CA (2000b) Dynamics of hippocampal ensemble realignment: time versus space. J Neurosci 20:9289-9309.

Rosenzweig ES, Redish AD, Bohanick JD, McNaughton BL, Barnes CA (1999) Behavioral correlates of hippocampal map realignment. Soc Neurosci Abstr 25:2165.

Rotenberg A, Mayford M, Hawkins RD, Kandel ER, Muller RU (1996) Mice expressing activated CaMKII lack low frequency LTP and do not form stable place cells in the CA1 region of the hippocampus. Cell 87:1351-1361.

Sharp PE, Blair HT, Etkin D, Tzanetos DB (1995) Influences of vestibular and visual motion information on the spatial firing patterns of hippocampal place cells. J Neurosci 15:173-189.

Skaggs WE, McNaughton BL (1998) Spatial firing properties of hippocampal CA1 populations in an environment containing two visually identical regions. J Neurosci 18:8455-8466.

Thompson LT, Best PJ (1989) Place cells and silent cells in the hippocampus of freely-behaving rats. J Neurosci 9:2382-2390.

Vanderwolf CH (1971) Limbic-diencephalic mechanisms of voluntary movement. Psychol Rev 78:83-113.

Wilson MA, McNaughton BL (1993) Dynamics of the hippocampal ensemble code for space. Science 261:1055-1058.

Wilson MA, McNaughton BL (1994) Reactivation of hippocampal ensemble memories during sleep. Science 265:676-679.

Witter MP (1993) Organization of the entorhinal-hippocampal system: a review of current anatomical data. Hippocampus 3:33-44.

Ylinen A, Bragin A, Nadasdy Z, Jando G, Szabo I, Sik A, Buzsáki G (1995) Sharp wave-associated high-frequency oscillation $(200 \mathrm{~Hz})$ in the intact hippocampus: network and intracellular mechanisms. J Neurosci 15:30-46. 